\title{
Implementasi Pendidikan Karakter Anak Usia Dini melalui Metode Bermain Peran Usia 5-6 Tahun di Taman Kanak-Kanak An-Nahl Bandar Lampung
}

\author{
Devi Sofa Nur Hidayah ${ }^{1)}$, Cahniyo Wijaya Kuswanto ${ }^{2)}$ \\ Universitas Islam Negeri Raden Intan \\ email: devi.sofanur22@gmail.com
}

\begin{abstract}
Abstrak
karakter

Pendidikan karakter dianggap sangat penting untuk ditanamkan pada anak sejak usia dini. Mengingat pentingnya membentuk nilai-nilai karakter ini, pendidikan dapat dikembangkan oleh guru dengan menerapkan pendidikan karakter melalui metode bermain peran. Rumusan masalah yang diusulkan peneliti adalah bagaimana menerapkan pendidikan karakter untuk anak usia dini melalui metode bermain peran berusia 5-6 tahun di TK An-Nahl Bandar Lampung. Tujuan dari penelitian ini adalah untuk mengetahui tentang bagaimana penerapan pendidikan karakter melalui metode bermain peran anak usia dini di TK An-Nahl Bandar Lampung. Metode penelitian ini menggunakan pendekatan deskriptif kualitatif yang melibatkan 1 guru dan jumlah 14 anak sedangkan objek penelitian adalah penerapan pendidikan karakter anak usia dini melalui metode bermain peran usia 5-6 tahun di TK An-Nahl Bandar Lampung, data dikumpulkan melalui observasi, wawancara, dan dokumentasi.Hasil penelitian menunjukkan bahwa pelaksanaan pendidikan karakter melalui metode bermain peran adalah sebagai berikut dengan langkah-langkah: (1) Guru Mengumpulkan Anak-Anak untuk Memberikan Arahan dan Aturan Bermain, (2) Guru membahas Alat yang Akan Digunakan oleh AnakAnak untuk Bermain, (3) Guru Membagikan Tugas kepada Anak-Anak Sebelum Bermain Menurut Kelompok Agar Tidak Bertengkar, (4) Guru Mengumpulkan Anak-Anak Untuk Dipandu, Memberikan Aturan dalam Game, Mendampingi Dan Menghitung Anak-Anak, (5) Pendidik Hanya Menonton Atau Menemani Anak-Anak Dalam Bermain Peran, (6) Anak-Anak Bermain Seperti Saat Ini, Anak-Anak Dapat Beralih Saat Bosan. Berdasarkan hasil penelitian bahwa perkembangan karakter pendidikan anak yang belum berkembang (0), mulai berkembang (5), berkembang sesuai harapan (6), berkembang sangat baik (3). Penelitian ini menggambarkan bagaimana proses guru dalam mengimplementasikan pendidikan karakter anak dan dapat digunakan sebagai sumber alternatif dalam proses implementasi pendidikan karakter untuk anak usia dini.
\end{abstract}

Kata Kunci: Pendidikan Karakter, metode bermain peran, anak usia dini 


\title{
Implementation of Early Children Character Education Through the Role Playing Method of Age 5-6 Years in Taman Kanak-Kanak An-Nahl Bandar Lampung)
}

\begin{abstract}
Character education is considered very important to instill in children from an early age. Given the importance of forming these character values, character education can be developed by teachers by implementing character education through role playing methods. The formulation of the problem that the researchers proposed was how to implement character education for early childhood through the role playing method aged 5-6 years in An-Nahl Bandar Lampung Kindergarten. The purpose of this study was to find out about how the implementation of character education through the method of playing the role of early childhood in An-Nahl Bandar Lampung Kindergarten.

This research method uses a qualitative descriptive approach involving 1 teacher and the number of 14 children while the object of the research is the implementation of early childhood character education through role playing methods aged 5-6 years at An-Nahl Bandar Lampung Kindergarten, data collected through observation, interviews, and documentation.

The results of the study show that the implementation of character education through role playing methods is as follows with the steps: (1) The Teacher Gathered the Children to Give Direction and Rules of the Play, (2) The teacher discusses the Tools that Will Be Used by Children to Play, (3) The Teacher Shares the Assignment to Children Before Playing According to Groups To Not Fight, (4) Teachers Gather Children To Be Guided, Give Rules In Games, Accompany And Calculate Children, (5) Educators Only Watch Or Accompany Children In Role Playing, (6) Children Play As They Are, Children Can Switch When Bored. Based on the results of the study that the development of the character education of children who have not yet developed (0), began to develop (5), developed according to expectations (6), developed very well (3). This research describes how the teacher processes in implementing child character education and can be used as an alternative source in the process of implementing character education for early childhood.
\end{abstract}

Keywords: Character Education, Role Playing Methods, Early Childhood.

\section{PENDAHULUAN}

Pendidikan karakter pada dasarnya saat ini merupakan topik yang sangat penting diperbincangkan dikalangan pendidikan. Pendidikan karakter diyakini sebagai aspek dalam peningkatan sumber daya manusia
(SDM) karena turut menentukan kemajuan suatu bangsa. Sedangkan hadist nabi yang diriwayatkan oleh imam bukhori yang menyatakan bahwa :

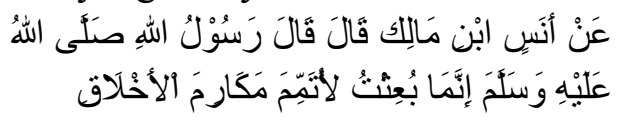


Artinya : dari malik bin anas, rasulullah SAW bersabda 'sesungguhnya aku diutus hanya untuk menyempurnakan akhlak'. (HR.Bukhori)

(Menurut Kamus Besar Indonesia 2008) istilah karakter bersifat sifat sifat kejiwaan, akhlak atau budi pekerti yang membedakan seseorang dari yang lain, tabiat, watak.Karakter secara etimologis berasal dari bahasa Yunani "karasso" yang berarti 'cetak biru', 'format dasar', 'sidik' seperti dalam sidik jari(Maksudin,2013). Menurut Thomas Lickona karakter merupakan sifat alami seseorang dalam merespon situasi secara bermoral (Agus Wibowo,2012), Sifat alami itu dimanifestikan dalam tindakan nyata melalui tingkah laku yang baik, jujur, bertanggung jawab, menghormati orang lain dan berkarakter mulia lainnya.

Bicara pendidikan karakter erat pula kaitannya dengan perkembangan moral anak, Suyanto menyebutkan bahwa perkembangan moral anak ditandai dengan kemampuan anak untuk memahami aturan, norma, dan etika yang berlaku (Suyanto,2015).

Pembentukan karakter anak di Tk An-Nahl Bandar Lampung sudah dilaksanakan melalui setiap materi setiap kegiatan yang melibatkan anak secara langsung. Pembelajaran yang dilakukan oleh guru tidak hanya menuntut mereka memiliki kompetensi kognitif saja akan tetapi juga memiliki kompetensi afektif dan disertai dengan memberikan pembiasaan, keteladanan, dan pendisplinan agar nilai yang diterapkan pada anak usia dini tersebut tertanam dalam dirinya sehingga menjadi pengalaman dalam kehidupan sehari hari, semua itu tidak akan berhasil jika menggunakan strategi yang tidak sesuai.

Dalam proses pembelajaran yang efektif, menyenangkan menarik dan bermakna bagi anak usia dini dipengaruhi oleh beberapa unsur antara lain guru yang memahami secara utuh hakikat, sifat dan karakeristik anak, metode pembelajaran yang berpusat pada kegiatan bermain sambil belajar, sarana belajar anak memadai, sumber belajar yang menarik dan mendorong anak untuk belajar sambil bermain yaitu salah satunya dengan metode bermain peran. Menurut Gilsrap dan martin dikutip oleh (Winda Gunarti Dkk,2010)bermain peran adalah memerankan karakter/tingkah laku dalam pengulangan kejadian yang diulang kembali, kejadian masa depan kejadian masa lalu masa kini yang penting, atau situasi imajinatif.

Menurut (MukhtarLatif,2014) metode bermain peran disebut juga main simbolik, role play, make believe, fantasi, imanjinatif atau main drama yang bertujuan untuk mengembangkan kemampuan interaksi sosial, kreativitas anak dan bahasa anak, membangun rasa empati, membangun abtrak berpikir dan berpikir secara objektif.

Berdasarkan pra Penelitian yang dilakukan oleh penulis di TK An-Nahl Bandar Lampung, anak masih terlihat kebiasaan dalam berbicara tidak jujur daat melakukan kesalahan, masih terlihat anak berebut mainan dengan temannya, masih terlihat anak datang terlambat datang kesekolah, anak masih menangis sesudah sampai sekolah dan tidak mau ditinggal oleh ibunya, anak masih 
membuang sampah sembarangan. Berikut hasil observasi yang diperoleh tentang keadaan karakter anak di TK AnNahl Bandar Lampung :

\section{Tabel I}

Hasil Pra Survey Perkembangan

Pendidikan Karakter Anak Usia Dini Melalui Metode Bermain Peran usia 5-6 tahun di Taman Kanak-Kanak An-Nahl Bandar Lampung

\begin{tabular}{|c|c|c|c|c|c|c|}
\hline & \multirow[t]{2}{*}{$\begin{array}{l}\text { nam } \\
\mathrm{a}\end{array}$} & \multicolumn{4}{|c|}{ Indikator Penilaian } & \multirow[t]{2}{*}{ KET } \\
\hline & & 1 & 2 & 3 & 4 & \\
\hline 1 & $\begin{array}{c}\text { AK } \\
\mathrm{H}\end{array}$ & MB & MB & MB & MB & MB \\
\hline 2 & ASF & $\mathrm{BB}$ & $\mathrm{BB}$ & MB & $\mathrm{BB}$ & BB \\
\hline 3 & $\mathrm{AD}$ & $\mathrm{BB}$ & $\mathrm{BB}$ & $\mathrm{BB}$ & $\mathrm{BB}$ & BB \\
\hline 4 & ATS & $\mathrm{BB}$ & $\mathrm{BB}$ & $\mathrm{BB}$ & $\mathrm{BB}$ & BB \\
\hline 5 & ASI & $\mathrm{MB}$ & $\mathrm{BB}$ & $\mathrm{BB}$ & BB & $\mathrm{BB}$ \\
\hline 6 & AAF & MB & MB & MB & MB & MB \\
\hline 7 & $\begin{array}{c}\text { CA } \\
\text { A }\end{array}$ & BB & MB & MB & $\mathrm{BB}$ & BB \\
\hline 8 & KTP & MB & MB & MB & MB & MB \\
\hline 9 & $\begin{array}{c}\text { KA } \\
\text { A }\end{array}$ & MB & $\mathrm{BB}$ & MB & $\mathrm{BB}$ & MB \\
\hline 10 & $\begin{array}{c}\text { NA } \\
\mathrm{R} \\
\end{array}$ & MB & $\mathrm{BB}$ & $\mathrm{BB}$ & $\mathrm{BB}$ & BB \\
\hline 11 & RA & $\mathrm{BB}$ & MB & $\overline{\mathrm{BSH}}$ & MB & $\mathrm{BSH}$ \\
\hline 12 & SK & MB & BB & BB & BB & BB \\
\hline 13 & TRF & $\mathrm{BB}$ & MB & MB & MB & MB \\
\hline 14 & $\begin{array}{c}\text { ZSC } \\
\text { R }\end{array}$ & $\mathrm{BSH}$ & $\mathrm{BSH}$ & MB & $\mathrm{BSH}$ & BSB \\
\hline
\end{tabular}

Keterangan :

1. Disiplin

2. Jujur

3. TanggungJawab

4. BekerjaSama

Keterangan :

\begin{tabular}{rlr} 
BB : & Belum & \multicolumn{2}{c}{ Berkembang Anak } \\
& mampu melakukan kegiatan \\
& dengan sendiri skor $50-59$ \\
& mendapatkan skor 1.
\end{tabular}

MB : Mulai Berkembang Anak sudah mulai mampu melakukan kegiatan dengan bantuan orang lain indikator penilaian skor 60 69 mendapatkan skor 2.

BSH : Berkembang Sesuai Harapan Anak mampu melakukan kegiatannya sendiri dengan skor 70-79 mendapatkan skor 3 .

BSB : Berkembang Sangat Baik Anak mampu melakukan kegiatan sendiri secara konsisten nilai 80-100 mendapatkan skor 4.

Berdasarkan tabel di atas terlihat berkembangnya karakter pada anak kelompok usia 5-6 tahun di Taman Kanak-Kanak An-Nahl Bandar Lampung pada kelas B masih banyak yang belum berkembang dari 6 peserta. Yang Berkembang Sangat Baik dapat diketahui ada 1 anak 7\%, Berkembang Sesuai Harapan dapat diketahui ada 1 anak 7\%, Mulai Berkembang dapat diketahui ada 5 anak 35\%, Belum Berkembang dapat diketahui ada 7 anak $50 \%$.

\section{METODE}

Penelitian ini dilakukan di TK AN-NAHL Bandar Lampung yang beralamat di Jl. Kepodang, Susunan Baru Tanjung Karang Barat dan dilaksanakan pada semester genap 2018/2019. Penelitian ini merupakan penelitian kualitatif deskriptif adalah metode penelitian yang digunakan untuk meneliti pada kondisi obyek alamiah, dimana peneliti adalah sebagai instrumen kunci, teknik pengumpulan data dilakukan secara triangulasi 
gabungan, analisis data bersifat induktif dan hasil penelitian lebih menekankan pada generalisasi (Sugiyono,2014). Dengan Subjek penelitian ini adalah guru dan anak sebanyak 14 murid. Objek penelitian ini implementasi pendidikan karakter anak usia dini melalui metode bermain peran usia 5-6 tahun di TK AnNahl Bandar Lampung. Teknik pengumpulan data melalui observasi, wawancara dan dokumentasi.

Teknik analisis data nya melalui reduksi data, penyajian data dan menyimpulakan (Sugiyono,2017) dan yang terakhir adalah triangulasi data.

\section{HASIL DAN PEMBAHASAN}

Berdasarkan hasil penelitian untuk mengetahui lebih lanjut bagaimana impelementasi pendidikan karakter anak usia dini di Tk An-Nahl Bandar Lampung, Menurut Yuliana Nuraini dan Bambang Sujiono langkahlangkah bermain peran diantaranya sebagai berikut :

1. Guru Mengumpulkan Anak Untuk Diberikan Pengarahan Dan Aturan Main.

Berdasarkan hasil wawancara oleh guru kelas yang diperoleh Sebelum pembelajaran berlangsung kami selalu mempersiapkan rpph terlebih dahulu agar pembelajaran bias berlangsung secara terstruktur dan rapih, sehingga tujuan pembelajaran mampu tercapai dengan baik. Tk AnNahl Bandar Lampung selalu menyiapkan rpph sebelum dimulainya kegiatan pembelajaran.RPPH.
2. Guru membicarakan Alat-alat Yang Akan Digunakan Oleh Anak-Anak Untuk Bermain.

Peneliti menyimpulkan bahwasannya di Tk An-Nahl Bandar Lampung selalu mempersiapkan terlebih dahulu alat dan bahan media dalam pembelajaran sebelum dimulainya pembelajaran tersebut.

\section{Guru memberikan pengarahan} sebelum bermain dan mengabsen serta menghitung jumlah anak.

Guru telah mengumpulkan anak sebelum bermain akan dimulai, dan memberikan arahan aturan bermain agar anak tidak salah dalam bermain dan menhitung jumlah peserta didik untuk di bagikan kelompok dan tugasnya.

4. Guru Membagikan Tugas Kepada Anak Sebelum Bermain Menurut Kelompok Agar Tidak Berebut.

Disimpulkan bahwa sebelum dilakukan bermain peran maka pendidik membagikan tugas kepada anak dengan tujuan agar anak mampu melakukan perannya dengan baik dan tidak berebut saat memerankannya.

5. Guru menyiapkan alat-alat permainan sebelum anak bermain Guru telah menyiapkan serta menyusun alat permainan sesuai dengan peraanyaa kan memudahkan anak untuk mengelompokkan peralatan bermain sesuai peraannya yang akan dimainkan agar tidak saling berebut.

6. Anak bermain dengan tempatnya, anak dapat berpindah tempat 
apabila merasa bosan dengan peran sebelumnya.

bahwasannya guru kelas B1 di Tk An-Nahl Bandar Lampung telah melakukan aturan langkah bermain peran yang sesuai, guru tidak terlalu ikut campur dalam anak bermain peran dan hanya mendampingi dan anak diperbolehkan pindah tempat apabila anak bosan.

7. Pendidik Hanya Mengawasi Atau Mendampingi Anak Dalam Bermain Peran

Pendidik Tk An-Nahl Bandar Lampung hanya mengawasi dan sedikit member bantuan kepada anak yang kebingungan dan kesulitan karena tujuan untuk mengembangkan imajinasi anak dan belajar secara optimal dalam mengekspresikan perannya. Lalu guru di Tk An-Nahl Bandar Lampung juga selalu melakukan evaluasi pembelajaran dan melakukan diskusi nilai-nilai karakter yang terkandung dalam kegiatan peran tersebut, dengan tujuan agar anak mampu meneladani sikap dan karakter yang terkandung dalam kegiatan bermain peran tersebut.

Berdasarkan hasil perkembangan anak sesuai indikator adalah (1) anak sabar dalam menunggu, (2) Anak tidak berebutan dalam bermain, (3) Anak meminta maaf saat melakukan kesalahan. (4) Anak menaati peraturan permainan, (5) Anak membereskan mainan pada tempatnya, (6) Anak dapat bekerja sama dalam bermain.
Setelah dilakukan upaya yang maksimal dari guru kelas B1 dengan berdasarkan langkah-langkah serta indicator pencapaian yang sesuai dengan mengenai implementasi pendidikan karakter anak usia dini melalui metode bermain peran, maka penulis mendapati hasil data observasi akhir sebagai berikut:

\section{Tabel 2}

Data penilaian implementasi pendidikan karakter anak usia dini melalui metode bermain peran usia 56 tahun di Taman Kanak-Kanak AnNahl Bandar Lampung

\begin{tabular}{|c|c|c|c|c|c|c|}
\hline \multirow[t]{2}{*}{ No } & \multirow[t]{2}{*}{ Nama } & \multicolumn{4}{|c|}{$\begin{array}{l}\text { Indikator Pencapaian Karakter } \\
\text { Anak }\end{array}$} & \multirow[t]{2}{*}{ KET } \\
\hline & & 1 & 2 & 3 & 4 & \\
\hline 1 & Alifa & MB & MB & $\mathrm{BSH}$ & MB & MB \\
\hline 2 & Almira & BSH & BSH & BSH & BSH & BSH \\
\hline 3 & Aluna & BSH & BSH & MB & MB & MB \\
\hline 4 & $\begin{array}{l}\text { Aqueni } \\
\mathrm{e}\end{array}$ & MB & BSH & MB & MB & MB \\
\hline 5 & $\begin{array}{l}\text { Ayla } \\
\text { Tevi }\end{array}$ & BSH & BSH & BSB & BSH & BSH \\
\hline 6 & Adinda & BSH & BSH & BSB & MB & BSH \\
\hline 7 & Chika & BSB & $\mathrm{BSH}$ & $\mathrm{BSH}$ & MB & BSH \\
\hline 8 & Kayla & BSH & BSB & BSB & MB & $\mathrm{BSH}$ \\
\hline 9 & Khanza & $\mathrm{BSH}$ & BSB & BSB & BSB & BSB \\
\hline 10 & Nada & BSH & MB & BSH & BSH & MB \\
\hline 11 & Raisha & BSH & BSH & BSH & BSH & BSH \\
\hline 12 & Siti & BSH & MB & BSH & BSH & MB \\
\hline 13 & Tasya & BSB & BSB & BSH & BSH & BSB \\
\hline 14 & Zivana & BSH & BSB & $\begin{array}{l}\mathrm{B} \\
\mathrm{S} \\
\mathrm{H}\end{array}$ & BSB & BSB \\
\hline
\end{tabular}

Sumber : Hasil Observasi di Taman Kanak-Kanak An-Nahl Bandar Lampung Tanggal 12 Mei 2019

Keterangan indikator :

1. Displin 
2. Jujur

3. BertanggungJawab

4. BekerjaSama

Keterangan Huruf :

BB : Belum Berkembang
MB : Mulai Berkembang
BSH : Berkembang Sesuai Harapan
BSB : Berkembang Sangat Baik

Berdasarkan dari hasil nilai diatas maka dapat penulis presentasikan untuk memudahkan dalam melihat hasil akhir yaitu sebagaiberikut :

Tabel 3 Hasil presentasi implementasi pendidikan karakter anak usia dini di Taman Kanak-Kanak An-Nahl Bandar Lampung

\begin{tabular}{|c|c|c|c|}
\hline No & Keterangan & $\begin{array}{l}\text { Jumlah } \\
\text { Anak }\end{array}$ & $\begin{array}{l}\text { Pres } \\
\text { enta } \\
\text { se } \\
\end{array}$ \\
\hline 1 & $\begin{array}{l}\text { BB (Belum } \\
\text { Berkembang) }\end{array}$ & 0 & $0 \%$ \\
\hline 2 & $\begin{array}{l}\text { MB (Mulai } \\
\text { Berkembang) }\end{array}$ & 5 & $\begin{array}{l}36 \\
\%\end{array}$ \\
\hline 3 & $\begin{array}{l}\text { BSH (Berkembang } \\
\text { Sesuai Harapan) }\end{array}$ & 6 & $\begin{array}{l}42 \\
\%\end{array}$ \\
\hline 4 & $\begin{array}{l}\text { BSB (Berkembang } \\
\text { Sangat Baik) }\end{array}$ & 3 & $\begin{array}{l}21 \\
\%\end{array}$ \\
\hline $\begin{array}{l}\text { Sum } \\
\text { Pres } \\
\text { Tam } \\
\text { Lam }\end{array}$ & $\begin{array}{l}\text { : Hasil } \\
\text { entasi Anak Usi } \\
\text { ung Kanak-Kanai }\end{array}$ & $\begin{array}{l}\text { Observa } \\
\text { lini kel } \\
\text { ln-Nahl }\end{array}$ & $\begin{array}{l}i \quad d a n \\
s \text { Bl di } \\
\text { Bandar }\end{array}$ \\
\hline
\end{tabular}

Berdasarkan tabel diatas dapat dipahami bahwasannya tingkat peserta didik anak sabar menunggu giliran, anak tidak berebutan dalam bermain, anak meminta maaf saat melakukan kesalahan, anak menaati aturan permainan, anak membereskan mainannya pada tempatnya. Berdasarkan hasil persentasi secara keseluruhan bahwasannya anak yang belum berkembang ( 0 ), anak yang mulai berkembang 5 (35\%), anak berkembang sesuai harapan 6 ( 42\%), anak berkembang sangat baik 3 ( $21 \%)$.

Dapat disimpulkan bahwasannya guru telah berusaha semaksimal mungkin dengan melakukan penggunaan metode bermain peran untuk mengembangkan dan menerapkan pendidikan karakter anak usia dini. Langkah-langkah yang diterapkan bermain peran untuk anak usia dini dalam mengimplementasikan pendidikan karakter di Taman KanakKanak An-Nahl Bandar Lampung telah menunjukkan hasil yang optimal.

\section{KESIMPULAN}

Berdasarkan hasil penelitian yang peneliti lakukan selama 30 hari di Taman Kanak-Kanak An-Nahl Bandar Lampung maka dapat disimpulkan bahwa implementasi pendidikan katrakter anak usia dini melalui metode bermain peran usia 5-6 Tahun di kelas B1 Taman Kanak-Kanak An-Nahl Bandar Lampung dapat dikatakan sudah efektif dan berjalan dengan baik, yaitu berdasarkan temuan yang diperoleh oleh peneliti dengan melihat langkah-langkah bermain peran yang dilakukan oleh guru, 
guru mengumpulkan anak untuk diberikan pengarahan dan aturan main, guru membicarakan alat-alat yang akan digunakan oleh anak untuk bermain, guru membagikan tugas kepada anak sebelum bermain menurut kelompok agar tidak berebutan, guru mengumpulkan anak untuk diberi pengarahan, memberi aturan dalam permainan dan mengabsen serta menghitung jumlah anak, pendidik hanya mengawasi atau mendampingi anak dalam bermain peran, anak bermain sesuai dengan tempatnya, anak bisa berpindah tempat apabila bosan.

\section{SARAN}

Berdasarkan hasil penelitian tersebut, peneltii menyampaikan saran sebagai berikut :

1. Bagi guru

Guru dapat lebih memperhatikan lagi anak-anak ketika bermain peran dan memberikan kebebasan terhadap anak dalam memilih peran yang disukainya dan membag itu gas peran dengan adil seadilnya, melakukan peran sesuai dengan langkah-langkah pelaksanaan metode bermain peran yang sudah ditentukan dan menurut teori yang ada dan tidak lupa pula bahwa pemberian atau penguatan seperti pemberian riwerd atau hadiah kepada anak setelah selesainya pembelajaran peneliti rasa sangat perlu untuk meningkatkan dan menumbuhkan semangat anak-anak serta jangan lupa pula untuk mengumpulkan anak untuk diberi pengarahan dan aturan dalam bermain.

2. Bagisekolah

Sekolah dapat meningkatkan kembali pengembangan programprogram yang menunjang adanya metode bermain peran untuk menerapkan pendidikan karakter anak, dan juga pembelajaran lain yang dapat menunjang pendidikan karakter anak, pembelajaran metode bermain peran sebaiknya tidak hanya dilakukan disela-sela pembelajaran tapi menjadikan satu kesatuan yang utuh dalam pembelajarannya tersebut.

3. Bagi peneliti

Peneliti tentang implementasi pendidikan karakter anak usia dini melalui metode bermain peran masih sangat jauh dari kata-kata sempurna masih banyak sekali kekurangan yang harus ditingkatkan lagi, oleh sebab itu diharapkan peneliti-peneliti selanjutnya hendaknya memotivasi dan member pengarahan untuk melakukan metode bermain perantujuannya agar metode ini lebih digunakan lagi untuk meningkatkan dan melengkapi pembelajaran serta media pembeljaran yang lebih baik dan bervariasi agar anak tidak bosan dan menerapkan pendidikan karakter anak sejak dini.

\section{DAFTAR PUSTAKA}

[1] Agus Wibowo, Pendidikan Karakter Strategi Membangun Karakter Bangsa Berperadaban, Yogyakarta: Pustaka Belajar,2012 
[2] Maksudin, Pendidikan Karakter Non-Dikotomi, Yogyakarta: PustakaBelajar, 2012

[3] Sugiyono, Metode pendidikan (pendekatan kuantitatif, Kualitatif, $R \& D$ (Bandung: Alfabeta 2017

[4] Sugiyono, Metode Penelitian Kuantitatif, Kualitatif, dan $R \& D$, (Bandung: Alfabeta, 2017

[5] Thomas Lickona, Pendidikan Karakter, Panduan Lengkap Mendidik Siswa Menjadi Pintar Dan Baik, Ter. Juma Abdu Wamaungo, (Bandung: Nusa Media,2013

[6] WindaGunarti, Metode pengembangan perilaku dan kemampuan dasar anak usia dini (tangerang: universitas Terbuka, 2017

[7] Yuliana Nurani Sujiono, Metode Pengembangan Kognitif, (Tangerang Selatan: Universitas Terbuka, 2017 